\title{
RESPONSABILIDAD SOCIAL DE LA EMPRESA HERDEZ COMO PARTE DE SU PLANECIÓN ESTRATEGICA.
}

\author{
M.C. Ma. Elsa Jiménez Fernández ${ }^{1}$ \\ ${ }^{1}$ Estudiante de Doctorado en Administración Estratégica Empresarial- Universidad \\ Latinoamericana en Línea. Correo electrónico: maelsaj@yahoo.com.mx.dtrujillv@yahoo.com.mx \\ DOI https://doi.org/10.46589/rdiasf.vi35.384 \\ Recibido 26 de febrero 2021. \\ Aceptado 20 de mayo 2021 \\ Publicado 30 de junio de 2021
}

\section{Resumen}

La empresa Herdez es líder en el sector de alimentos procesados y líder en comida mexicana en Estados Unidos.

La misión, visión y valores reflejan su compromiso con los clientes y socios.

Uno de los eventos importantes en la historia de la responsabilidad social de las empresas fue la Revolución Industrial, donde la responsabilidad empresarial no incluía el término social, sin embargo, este tema no es actual ya que desde el siglo XVIII fue considerada por los economistas clásicos como Smith, Marx, Owen entre otros y ha evolucionado por la situación ambiental social global, presión por los grupos de interés y la filantropía empresarial. En México los orígenes de la Responsabilidad Social se ubican hacia mediados del Siglo XX a insistencia de la COPARMEX y AC (USEM), además, es una nueva forma de hacer negocios que genera valor y prestigio a las empresas.

Algunos de los proyectos que desarrolla Herdez como empresa socialmente responsable son: generación de energía eólica para sus procesos, manejo de residuos, ahorro de agua, instalaciones economizadoras de combustible en calderas para evitar la generación de $\mathrm{CO} 2$, uso de gas natural. Otras actividades son uso de tecnologías limpias para evitar el daño al medio ambiente.

Además de lo anterior, tiene programas sociales en beneficio de las habitantes de la región donde está instalada, como los programas de educación nutrimental, compite, entre otros. 
Palabras clave: Economistas, energía eólica, residuos, filantropía, sociedad.

Abstract

The Herdez company is a leader in the processed food sector and a leader in Mexican food in the United States.

The mission, vision and values reflect its commitment to clients and partners.

One of the important events in the history of corporate social responsibility was the Industrial Revolution, where corporate responsibility did not include the term social, however, this issue is not current since since the 18th century it was considered by classical economists like Smith, Marx, Owen among others and has evolved by the global social environmental situation, pressure by interest groups and corporate philanthropy. In Mexico, the origins of Social Responsibility are located towards the middle of the 20th century at the insistence of COPARMEX and AC (USEM), in addition, it is a new way of doing business that generates value and prestige to companies.

Some of the projects that Herdez develops as a socially responsible company are: generation of wind energy for its processes, waste management, saving water, fuel-saving installations in boilers to avoid the generation of $\mathrm{CO} 2$, use of natural gas. Other activities are the use of clean technologies to avoid damage to the environment.

In addition to the above, it has social programs for the benefit of the inhabitants of the region where it is installed, such as nutritional education programs, it competes, among others.

Keywords: Economists, wind energy, waste, philanthropy, society.

\section{Introducción}

La empresa Herdez es líder en el sector de alimentos procesados, uno de los principales jugadores en la categoría de helados en México, y líder en comida mexicana en Estados Unidos. Los productos se comercializan a través de un amplio portafolio de marcas. Su misión, visión y valores reflejan su compromiso con los clientes y socios.

Uno de los eventos importantes en la historia de la responsabilidad social de las empresas fue la Revolución Industrial, donde la responsabilidad empresarial no incluía el término social. 
Actualmente se ha dado especial importancia a la responsabilidad social de las empresas, sin embargo, este tema no es actual, ya que desde el siglo XVIII fue considerada por los economistas clásicos como Roberto Owen que defendió la necesidad de crear procesos productivos socialmente responsables en relación a la empresatrabajador; Carlos Marx critico el sistema capitalista; Adam Smith plantea que los negocios deben conducirse de forma ética conforme a las reglas éticas básicas de la sociedad; Milton Friedman, su posición es reduccionista. En las últimas décadas, la Responsabilidad Social ha evolucionado por la situación ambiental social global, presión por los grupos de interés y la filantropía empresarial.

En México los orígenes de la Responsabilidad Social se ubican hacia mediados del Siglo XX por la insistencia de la COPARMEX y la AC (USEM).

La Responsabilidad social Empresarial es una nueva forma de hacer negocios que genera valor y da prestigio a las empresas.

El objetivo del trabajo es investigar las condiciones de responsabilidad Social corporativa que la empresa Herdez considerada desde su planeación estratégica, para lo cual, la metodología es conceptual, teórica y de análisis de diferentes conceptos referentes al tema.

Posteriormente, se detallan los proyectos que desarrolla la empresa, mismos por lo que se considera que es socialmente responsable; estos son generación de energía eólica para sus procesos, manejo de residuos, ahorro de agua, instalaciones economizadoras de combustible en calderas para evitar la generación de $\mathrm{CO} 2$, uso de gas natural. Otras actividades son uso de tecnologías limpias para evitar el daño al medio ambiente, cuenta con programas de educación nutrimental y la Fundación Herdez que promueve el conocimiento alimentario y nutricional. El programa "COMPITE" difunde las competencias institucionales en beneficio de los colaboradores y de la proyección de la institución.

El taller "Líder Herdez" para el trato digno por parte del líder a sus colaboradores. Como propuesta de valor, sus ventajas competitivas más importantes son la calidad y el liderazgo de portafolio que maneja.

En cuanto a Ética y transparencia, la empresa se encarga de reforzar la cultura de legalidad con todos los grupos de interés. 


\section{Planteamiento del problema}

Los grupos de interés en las empresas son los que forman parte de todas sus actividades y tienen influencia en ellas, por esta razón se deben atender, ya que de ellos depende en gran medida su éxito y permanencia, por otra parte, para las empresas es importante que realicen acciones de filantropía, siendo esta una manera de contribuir en beneficio a la sociedad.

Con base a lo expuesto la interrogante en este trabajo es ¿Cuáles son las actividades que realiza la empresa Herdez como Empresa Socialmente Responsable??

\section{Antecedentes}

\section{Origen y concepto de la responsabilidad social corporativa.}

Décadas atrás, las ciencias sociales no tenían como parte de su objeto de estudio las empresas ya que solo eran consideradas como fuentes de explotación de trabajo.

Solo hasta los años 80 la sociedad comenzó a interrogar a las organizaciones por sus comportamientos. Para los años 90 la discusión se abría en torno a la función social de las empresas y su responsabilidad con la sociedad en general y el medioambiente. Han transcurrido cerca de 30 años sobre los que se han gestado avances alrededor del tema de la RS y se han incrustado en el lenguaje de la administración, y, pese a ello, todavía no se tiene un sustrato conceptual sólido, al menos, compartido entre los autores (Avendaño W. , 2013)

La Responsabilidad Social Empresarial (RSE) es una nueva forma de hacer negocios ya que es una manera de generar valor agregado que la empresa ofrece a la sociedad en general y que a mediano o largo plazo estas acciones se conviertan en una ventaja competitiva, creando una imagen positiva de la organización y de esta manera garantizar su permanencia y consolidación en el ámbito empresarial (Valdez, S/F)

La significación de responsabilidad social corporativa (RSC) o empresa socialmente responsable (RSE) ha pasado de ser un concepto abstracto y mal entendido, a ser un apellido que otorga prestigio a las empresas que deciden adoptarlo. Pero la evolución no se detiene en este punto. Las empresas han adoptado y adaptado esta concepción con el objetivo de seguir lucrándose con sus actividades empresariales, pero 
poseyendo un argumento perfecto para venderse ante una sociedad cada vez mejor educada en temas sociales y medioambientales: ser socialmente responsable o, lo que es lo mismo, buena con el entorno más próximo que le rodea y en el que crece. (Gómez B. , 2016)

\section{Justificación}

La presente investigación se desarrolla con la finalidad de conocer el compromiso de la empresa Herdez con la responsabilidad social, ya que como cualquier empresa, debe dar a conocer o comunicar sus esfuerzos para lograr una vinculación positiva con sus grupos de interés, que es una ventaja competitiva ante ellos y ante la sociedad, logrando con esto tener más prestigio, y esa percepción por parte de la sociedad, motiva a consumir lo que la empres produce valorando el interés que tiene para la conservación del medio ambiente y por los colaboradores, en general, por la sociedad.

\section{Objetivo}

Investigar las condiciones de la responsabilidad Social Corporativa que la empresa Herdez considera desde su planeación estratégica.

\section{HERDEZ}

Grupo Herdez, S.A.B. de C.V. es una sociedad mercantil que cotiza desde 1991 en la Bolsa Mexicana de Valores desde 1997 en el mercado OTC (Over the Counter) Es líder en el sector de alimentos procesados y uno de los principales jugadores en la categoría de helado en México, así como uno de los líderes en comida mexicana en Estados Unidos.

Sus oficinas centrales están ubicadas en Monte Pelvoux 215, Lomas de Chapultepec, C.P. 11000, México D.F. Opera y comercializa sus productos en nueve países; México, Estados Unidos, Canadá, Costa Rica, Cuba, El Salvador, Guatemala, Honduras y Nicaragua. (S/F, 2015) 
Participa en una amplia gama de categorías, entre las que se encuentran: alimentos orgánicos, atún, burritos, cátsup, especias, guacamole, helado, mayonesa, mermelada, miel, mole, mostaza, pasta, puré de tomate, salsas caseras, té y vegetales en conserva, entre otras.

Los productos se comercializan a través de un excepcional portafolio de marcas, entre las que destacan: Aires de Campo, Barilla, Búfalo, Chi-Chi's, Del Fuerte, Don Miguel, Doña María, Embasa, Helados Nestlé, Herdez, La Victoria, McCormick, Nutrisa, Wholly Guacamole y Yemina.

Adicionalmente, cuenta con acuerdos para la distribución en México de los productos de Herdez GoGoSqueez, Kikkoman, Ocean Spray, Reynolds y Truvía. Durante el año se inauguró la nueva planta de mayonesa en el Estado de México,

Misión Poner al alcance de los consumidores alimentos y bebidas de calidad, con marcas de prestigio y valor crecientes.

Visión Grupo Herdez quiere consolidarse, crecer y posicionarse como una organización líder en el negocio de alimentos y bebidas, reconocida por la calidad de sus productos y por la efectividad de sus esfuerzos orientados a asegurar la satisfacción de las necesidades y expectativas de sus consumidores, en un marco de atención y servicio competitivos para sus clientes, bajo estrictos criterios de rentabilidad, potencial estratégico y sustentabilidad.

Valores | Honestidad, Orientación a Resultados, Trabajo en Equipo y Confianza. (S/F, 2015)

\section{Referencias teóricas}

\section{Antecedentes históricos de la RSE}

La actividad empresarial está documentada como tal, al menos hace seis mil años, de acuerdo con los registros contables de los antiguos Sumerios.

\section{Algunos de los eventos y personajes que han marcado lugar en la historia de la RSE: \\ La revolución industrial.}


La ética empresarial no estaba preocupada por el peso de las prácticas industriales y comerciales sobre la comunidad y los recursos naturales. La responsabilidad empresarial no incluía el término "social".

En el siglo XVIII, Robert Owen defendió la necesidad de crear procesos productivos socialmente responsables en la relación empresa - trabajador, creía en la buena naturaleza de las personas, influenciadas por el ambiente, intentó con sus experimentos en New Lanark y New Harmony, mejorar la calidad de vida de los trabajadores de la industria textil, en apoyo total a la formación de sindicatos y sistemas cooperativos

Seguramente muchos estudiosos ubican a este personaje histórico como el primer empresario en pronunciarse a favor de la RSE a través de sus acciones.

Karl Marx - 1818- 1883- , criticó al sistema capitalista; su pensamiento está enfocado en una relación obrero - patronal. Sus denuncias van en la dirección de lo que considerara injusticias sociales hacia el proletariado.

Tanto Owen como Marx se enfocaron en la relación del empresario con el trabajador.

Adam Smith. Su teoría plantea que los negocios deben conducirse de forma ética conforme a las reglas básicas de la sociedad, refiriéndose al cumplimiento de las leyes, de donde derivan las normas de comportamiento moral y socialmente aceptado

Milton Friedman - 1912- 2006-. Su posición es reduccionista, donde los únicos a quienes hay que cumplirles es a los accionistas, bajo este enfoque, pensar en un espectro amplio que abarque empleados, medio ambiente y comunidad, pondría a la empresa en una posición poco atractiva para inversionistas

En las últimas décadas la necesidad de RSE ha evolucionado a partir de las siguientes causas:

Situación ambiental, social global y regional.

Presión ejercida por los grupos de interés.

Evolución de la filantropía empresarial. (S/F, S/F)

Los orígenes de la RSE en México habrá que ubicarlos hacia mediados del siglo XX. Dos organizaciones empresariales destacaron por su insistencia y pronunciamiento 
en el tema: la Confederación Patronal de la República Mexicana (COPARMEX) y la, en ese entonces, Uniones Sociales de Empresarios de México, A.C. (USEM). Ambas aportaron elementos teórico-prácticos para la fundamentación y desarrollo del concepto mismo. Más tarde, en 1992, el Centro Mexicano para la Filantropía (CEMEFI), creó el programa de Filantropía Empresarial con 6 empresas participantes. (Mejía, S/F)

Responsabilidad social. Es el reconocimiento e integración en sus operaciones por parte de las empresas, de las preocupaciones sociales y medioambientales, dando lugar a prácticas empresariales que satisfagan dichas preocupaciones y configuren sus relaciones con sus interlocutores (Avendaño, 2013)

Responsabilidad social Corporativa. La RSE o RSC es un término que hace referencia al conjunto de obligaciones y compromisos, legales y éticos que se derivan de la actividad de las organizaciones y con impacto en las esferas: social, laboral, medioambiental y de los derechos humanos, es decir, los ámbitos que señala el Pacto Global (Avendaño, 2013)

El Libro verde de La Comunidad Europea enfatiza que la RSE debe de ser considerada, como la integración voluntaria por parte de las empresas, de las preocupaciones sociales y medioambientales en sus operaciones comerciales y sus relaciones con sus interlocutores, lo que implica que para considerar a una empresa como socialmente responsable no solo debe de cumplir plenamente las obligaciones jurídicas, sino también, ir más allá de su cumplimiento invirtiendo «más» en el capital humano, el entorno y las relaciones con los interlocutores (Gómez, 2017)

La sustentabilidad. abarca tres esferas clave: social, económica y ambiental.

Actualmente se malinterpreta esto, dándole mucho peso a lo ecológico; sin embargo, para que algo pueda llamarse sustentable, debe ser completamente viable en las tres esferas. (Maram, 2013)

Innovación empresarial. El desarrollo tecnológico se puede clasificar a través de la intensidad de cómo se presenta la innovación: en incremental ( la innovación ayude a cambiar una tecnología existente pero no para cambiar su funcionalidad, mejorando el rendimiento, la función y / o la calidad a un costo menor, reforzando o mejorando algunos de sus componentes o conceptos; se conserva la ventaja competitiva) o radical(causa un dramático cambio en la manera de hacer las cosas, es decir, tanto la arquitectura como los componentes son alterados, de hecho se trata de un nuevo producto.) (Mejía, S/F) 
Filantropía. Es la palabra que designa al amor por el género humano que expresa una persona y que se manifiesta a través de una ayuda desinteresada al otro, especialmente a aquellos más vulnerables que demandan una asistencia.

La competitividad. Es la capacidad que tiene una empresa o país de obtener rentabilidad en el mercado con relación a sus competidores. La competitividad depende de la relación entre el valor y la cantidad del producto ofrecido y los insumos necesarios para obtenerlo (productividad), y la productividad de los otros oferentes del mercado. El concepto de competitividad se puede aplicar tanto a una empresa como a un país. (Anzil, 2008).

Medio ambiente. Es un sistema formado por elementos naturales y artificiales que están interrelacionados y que son modificados por la acción humana. Se trata del entorno que condiciona la forma de vida de la sociedad y que incluye valores naturales, sociales y culturales que existen en un lugar y momento determinado. (Marimar, 2020)

Creación de valor. Conjunto de actividades que aumentan el valor para los accionistas, incrementando la rentabilidad sobre el capital invertido, así como el valor de los bienes o el de los servicios para los consumidores. (S/F, S/F)

Planeación estratégica. Es una actividad administrativa y un proceso organizacional que define la dirección y el objetivo de una organización en el largo plazo. (Anzil, 2011)

Es un proceso sistemático, global y de largo plazo llevado a cabo por los dirigentes de la empresa, con la finalidad de establecer los cursos de acción para el logro de los objetivos institucionales. (Editorial, 2019)

\section{Metodología}

Se describe la metodología que es conceptual, teórica y de análisis de los contenidos, para lo cual se consultan diferentes fuentes bibliográficas con el fin de definir diversos conceptos como Responsabilidad Social, R.S Corporativa, Sustentabilidad, Innovación empresarial, Filantropía, Competitividad,

Medio ambiente, creación de valor y Planeación estratégica. 
Con esta información se facilitará conocer la situación del entorno de la empresa, así como su planeación estratégica en cuanto a las actividades que lleva a cabo como empresa socialmente responsable.

Grupo Herdez se compromete a generar productos alimenticios de alta calidad evitando afectaciones al medio ambiente y con responsabilidad social, a través de las siguientes acciones.

Cuenta con proyectos de generación de energía eléctrica a través de energía eólica, programas de manejo integral de residuos, reducción de consumo de agua y capacitación a empleados y proveedores, cuenta con un programa de sustitución de refrigerantes , así como proyectos de conversión e instalación de economizadores de combustible en calderas evitando la generación de aproximadamente 1, 669 toneladas de CO2, además se instalaran plantas de cogeneración que proveer de energía eléctrica y térmica a través del uso de gas natural (ninguna de las operaciones de grupo Herdez daña la capa de ozono. (Puerta, S/F)

Otras de las actividades como parte de esta responsabilidad social y como parte importante de las estrategias de la organización son:

1. La inversión comunitaria y mejorar el desempeño medioambiental, a través del uso eficiente de recursos y utilización de tecnologías más limpias en nuestras plantas y centros de distribución

2. Con la educación nutricional como principal línea de acción, Herdez Nutre evolucionó a Saber Nutrir con presencia en Chiapas, Guadalajara, Oaxaca y San Luis Potosí, tiene como meta conseguir un millón de horas de educación nutricional recibida por niños en edad escolar, padres de familia y equipo docente.

3.Fundación Herdez continuó con su labor de promover el conocimiento alimentario y nutricional al tiempo que busca rescatar y conservar el patrimonio de la gastronomía mexicana a través de diferentes cursos, talleres, publicaciones y alianzas con instituciones de educación superior.

4. Programa “COMPITE”, tiene la finalidad de difundir las Competencias Institucionales para que formen parte del comportamiento de los colaboradores en sus labores diarias y lograr distinguirnos como organización a través de ellas. 
5. El taller “Líder Herdez" es un esfuerzo que obedece al interés en el desarrollo del personal y el clima laboral de la organización para resaltar en nuestros líderes la importancia de un trato digno y equitativo a los colaboradores a su cargo (Hernández, 2011).

\section{Etica y responsanilidad social.}

Propuesta de valor. Las ventajas competitivas más importantes son la calidad y el liderazgo de portafolio, compuesto por más de 25 marcas y 1, 500 productos que participan en alrededor de 40 categorías. Grupo Herdez creó indicadores que le permiten medir de manera cuantificable su propuesta de valor y analizar objetivamente su crecimiento y avance. (Puerta, S/F)

Ética y transparencia. A través de nuestro pilar de ética y transparencia, año con año reforzamos la cultura de legalidad tanto en nuestros colaboradores como en nuestros proveedores y demás grupos de interés. A través de canales de denuncia y códigos de conducta, fomentamos un ambiente de trabajo y operaciones éticas, libres de soborno, corrupción y de cualquier falta a los derechos humanos. Para lograr este objetivo, a partir de este año decidimos unir esfuerzos con México Unido Contra la Delincuencia, asociación sin fines de lucro dedicada a trabajar en causas y acciones a favor de la seguridad, la justicia y la legalidad. (S/F, 2017).

\section{Conclusiones y propuestas}

Al término de este trabajo se puede apreciar que la Responsabilidad Social de la empresa Herdez se sustenta en los cuatro ejes necesarios para esto.

En cuanto a la ética y gobernabilidad, el taller de Líder Herdez está enfocado al desarrollo del líder en cuanto al trato digno y equitativo del personal a su cargo, lo que propicia un buen clima laboral.

La calidad de vida en la empresa se puede percibir a través del programa "COMPITE" que es con la finalidad de difundir las competencias institucionales para que formen parte del comportamiento de los empleados en sus labores diarias, lo cual beneficia también a la empresa, debido a que a través de ese comportamiento se puede distinguir o dar a conocer. 
Vinculación y compromiso con la comunidad y su desarrollo. Esto es a través del programa de educación nutricional que tiene como meta conseguir un millón de horas de educación de educación nutricional para niños en edad escolar, padres de familia y equipo decente.

Por otra parte, la Fundación Herdez una de sus actividades es promover el conocimiento alimentario y nutricional y al mismo tiempo busca rescatar y conservar el patrimonio de la gastronomía mexicana a través de diferentes cursos y alianzas con instituciones de educación superior.

En cuanto al cuidado y preservación del medio ambiente, la empresa genera energía eólica, tiene programas de manejo integral de residuos, ahorro de agua, cuenta con un programa de sustitución de refrigerantes, conversión e instalación de economizadores de combustible evitando la generación de $\mathrm{CO} 2$, ninguna de las operaciones daña la capa de ozono.

Todas estas estrategias de responsabilidad social le permiten a la empresa tener una proyección positiva tanto al interior (para los colaboradores) como al exterior (para los grupos de interés), ya que las ventajas competitivas más importantes son, la calidad y el liderazgo de portafolio con que cuenta.

La decisión de iniciar un negocio o empresa tienen como objetivo principal generar utilidades, sin embargo esto conlleva otros compromisos o responsabilidades de los cuales la empresa debe tener conocimiento, sobre todo en la actualidad cuando se está observando el daño que se hace al medio ambiente, es cuando las empresas deben incluir en sus objetivos de qué manera van a contribuir para evitar esto, ya que su compromiso no debe terminar o ser solo para obtener beneficios generados por su propia actividad, sino que además debe tener presente como mejorar su competitividad y añadir valor a lo que ofrece y el hecho de mostrar interés por la sociedad y el medio amiente representa una ventaja competitiva, sin embargo gran cantidad de empresas no lo ven de esta manera, sino que lo perciben solo como un gasto, lo que los lleva a actuar sin valores éticos, pensando solo en el beneficio económico, sin tomar en cuenta que este no se separa del beneficio social y ecológico.

Todo lo anterior debe ser incluido en el plan estratégico de la empresa. En el caso de Herdez, esto se percibe en la declaración de su visión y valores, mencionando que sus 
esfuerzos son orientados a la satisfacción de los consumidores pensando, primeramente, en la rentabilidad, pero además en su potencial estratégico y sustentabilidad y sus valores son honestidad, orientación a resultados, trabajo en equipo y confianza.

Cabe mencionar que no siempre las empresas se comportan de acuerdo a los compromisos declarados en la misión, visión y valores, muchas de ellas lo ven solo como requisito para obtener los beneficios que buscan y no se detienen a hacer un análisis del alcance de los beneficios que conlleva el desempeñarse como empresa socialmente responsable con ética, como en el caso de Herdez y cualquier otra empresa que integran en su plan estratégico la responsabilidad social como una de sus estrategias para crear valor, que además genera relaciones que le traen beneficios a largo plazo.

Finalmente, el actuar de las empresas con ética, filantropía y responsabilidad social, por una parte, genera una ventaja competitiva, pero además es un camino estratégico para crear valor, generando relaciones a largo plazo en beneficio de la empresa, lo que representa una ventaja competitiva, que lleva al incremento de las ventas, por lo tanto, incremento de utilidades.

Bibliografía

Anzil, F. (S/F 2008). Obtenido de Zona Económica: https://www.zonaeconomica.com/definicion/competitividad

Anzil, F. (S/F2011). Planeacion Estrategica. Obtenido de https://www.zonaeconomica.com/planeacion-estrategica

Avendaño, W. (2013). Responsabilidad social (RS) y responsabilidad social corporativa (RSC): una nueva perspectiva para las empresas . Rrevista Lasallista de Invstigacion. V0I 10, No.1, 2013, 3.

Avendaño, W. (2013). Responsabilidad social (RS) y responsabilidad social corporativa (RSC): una nueva perspectiva para las empresas . Revista Lasallista de Investigación., 155.

Editorial, E. (2019). Cuáles son los elementos de la Planeción Estratégica. Obtenido de https://reportedigital.com/negocios/emprendimiento/elementos-de-la-planeacionestrategica/

Gómez, B. (2016). Ethicl Values in Corporatives Social Responsability. AnagramasUniversidad de Medellin., 3.

Gómez, J. (2017). Politicas publicas y RenovaciónSocial enel Siglo XXI. México: HESS Grupo Editores.

Hernández, H. ( 2011). Relaciones de largo plazo. Obtenido de https://grupoherdez.com.mx/file/2015/09/informe_sustentabilidad_2011_es.pdf 
Maram, L. ( 2013). Diferencia entre responsabilidad social y sustentabilidad. Obtenido de https://www.luismaram.com/diferencia-entre-responsabilidad-social-y-sustentabilidad/

Marimar. ( 2020). El Blog Verde.com. Obtenido de https://elblogverde.com/el-medio-ambiente/ Mejía, J. (S/F). RESPONSABILIDAD SOCIAL CORPORATIVA E INNOVACIÓN: PROPUESTA DE DISEÑO PARA SU MEDICIÓN. Obtenido de http://gc.scalahed.com/recursos/files/r161r/w25021w/Responsabilidad\%20social_S2.pd $f$

Puerta, C. (S/F). Plan estrategico "Grupo Herdez". Universidad Aanahuac México Norte., 3.

S/F. ( 2015). Obtenido de http://grupoherdez2014.com/es/perfil-corporativo/

S/F. ( 2017). Resilencia y Enfoque 2017 Informe anual. Obtenido de http://grupoherdez2017.com/wp-content/uploads/2018/04/HERDEZ-I

S/F. (S/F de S/F de S/F). Marco Teorico de Responsabilidad social. Obtenido de https://webquery.ujmd.edu.sv/siab/bvirtual/Fulltext/ADMI0000738/C1.pdf

Valdez, R. (S/F). La responsabilidad social empresarial como modelo. S/F, 335.

Cómo citar este artículo:

Jiménez Fernández, E. (2021). Responsabilidad social de la empresa Herdez como parte de su planeación estratégica. Revista De Investigación Académica Sin Frontera: División De Ciencias Económicas Y Sociales, (35), 14. https://doi.org/10.46589/rdiasf.vi35.384

https://revistainvestigacionacademicasinfrontera.unison.mx/index.php/RDIASF/article/view/384

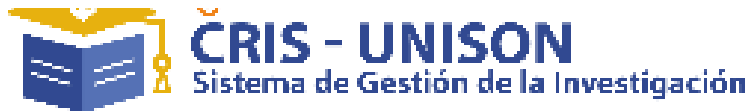

D Dianet

CiteFactor
If Iifactor

REDIB

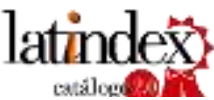

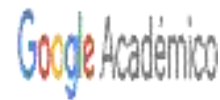

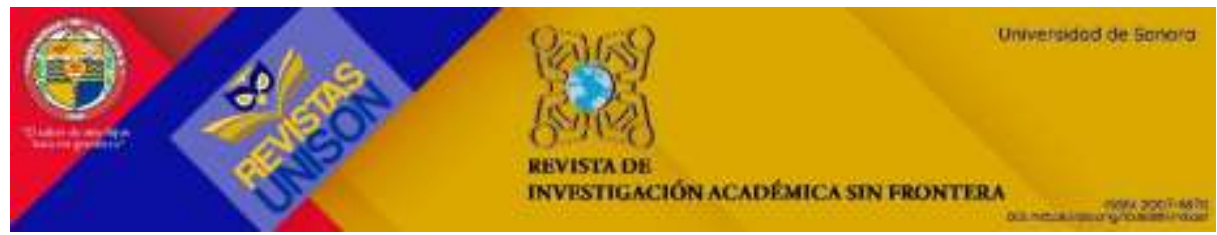

